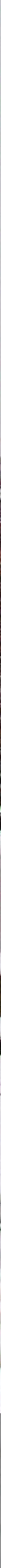




\section{EXPLAINING EXTREME EVENTS OF 20I4 FROM A CLIMATE PERSPECTIVE}

Editors

Stephanie C. Herring, Martin P. Hoerling, James P. Kossin, Thomas C. Peterson, and Peter A. Stott

Special Supplement to the

Bulletin of the American Meteorological Society

Vol. 96, No. 12, December 2015

American Meteorological Society 


\section{CORRESPONDING EDITOR:}

Stephanie C. Herring, PhD

NOAA National Climatic Data Center

325 Broadway, E/CC23, Rm IB-I3I

Boulder, CO, 80305-3328

E-mail: stephanie.herring@noaa.gov

\section{COVER CREDITS:}

Front: @iStockphotos.com/coleong-Winter snow, Boston Massachusetts, United States.

BACK: (OiStockphotos.com/nathanphoto-Legget, CA, United States - August 13 2014: CAL FIRE helicopter surveys a part of the Lodge Fire, Mendocino County.

\section{HOW TO CITETHIS DOCUMENT}

Citing the complete report:

Herring, S. C., M. P. Hoerling, J. P. Kossin, T. C. Peterson, and P.A. Stott, Eds., 20I 5: Explaining Extreme Events of 2014 from a Climate Perspective. Bull.Amer. Meteor. Soc., 96 (I2), SI-SI 72.

Citing a section (example):

Yoon, J. H., S.-Y. S. WANG, R. R. Gillies, L. Hipps, B. KRavitZ, and P. J. Rasch, 20I5: Extreme fire season in California: A glimpse into the future? [in "Explaining Extremes of 2014 from a Climate Perspective"]. Bull. Amer. Meteor. Soc., 96 (I2), S5-S9.

\section{EDITORIAL AND PRODUCTION TEAM}

Riddle, Deborah B., Lead Graphics Production, NOAA/NESDIS National Centers for Environmental Information, Asheville, NC

Love-Brotak, S. Elizabeth, Graphics Support, NOAA/NESDIS National Centers for Environmental Information, Asheville, NC

Veasey, Sara W., Visual Communications Team Lead, NOAA/ NESDIS National Centers for Environmental Information, Asheville, NC

Griffin, Jessica, Graphics Support, Cooperative Institute for Climate and Satellites-NC, North Carolina State University, Asheville, NC

Maycock, Tom, Editorial Support, Cooperative Institute for Climate and Satellites-NC, North Carolina State University, Asheville, NC
Misch, Deborah J., Graphics Support, LMI Consulting, Inc., NOAA/NESDIS National Centers for Environmental Information, Asheville, NC

Osborne, Susan, Editorial Support, LMI Consulting, Inc., NOAA/NESDIS National Centers for Environmental Information, Asheville, NC

Schreck, Carl, Editorial Support, Cooperative Institute for Climate and Satellites-NC, North Carolina State University, and NOAA/NESDIS National Centers for Environmental Information, Asheville, NC

Sprain, Mara, Editorial Support, LAC Group, NOAA/NESDIS National Centers for Environmental Information, Asheville, NC

Young, Teresa, Graphics Support, STG, Inc., NOAA/NESDIS National Centers for Environmental Information, Asheville, NC 


\section{TABLE OF CONTENTS}

Abstract

I. Introduction to Explaining Extreme Events of 2014 from a Climate Perspective ................................ I

2. Extreme Fire Season in California: A Glimpse Into the Future? ..............................................................5

3. How Unusual was the Cold Winter of 20I3/14 in the Upper Midwest?.............................................10

4. Was the Cold Eastern Us Winter of 2014 Due to Increased Variability? ...........................................15

5. The 2014 Extreme Flood on the Southeastern Canadian Prairies ....................................................... 20

6. Extreme North America Winter Storm Season of 2013/14: Roles of Radiative Forcing and the Global Warming Hiatus....................................................................................................................... 25

7. Was the Extreme Storm Season in Winter 2013/14 Over the North Atlantic and the United Kingdom Triggered by Changes in the West Pacific Warm Pool? ...................................................... 29

8. Factors Other Than Climate Change, Main Drivers of 2014/15 Water Shortage in Southeast Brazil.

9. Causal Influence of Anthropogenic Forcings on the Argentinian Heat Wave of December 2013

10. Extreme Rainfall in the United Kingdom During Winter 2013/14: The Role of Atmospheric Circulation and Climate Change...

II. Hurricane Gonzalo and its Extratropical Transition to a Strong European Storm............................5I

12. Extreme Fall 2014 Precipitation in the Cévennes Mountains .............................................................. 56

13. Record Annual Mean Warmth Over Europe, the Northeast Pacific, and the Northwest Atlantic During 2014: Assessment of Anthropogenic Influence.

14. The Contribution of Human-Induced Climate Change to the Drought of 2014 in the Southern Levant Region

15. Drought in the Middle East and Central-Southwest Asia During Winter 2013/14............................ I

16. Assessing the Contributions of East African and West Pacific Warming to the 2014 Boreal Spring East African Drought

17. The 2014 Drought in the Horn of Africa: Attribution of Meteorological Drivers............................. 83

18. The Deadly Himalayan Snowstorm of October 2014: Synoptic Conditions and Associated Trends.

19. Anthropogenic Influence on the 2014 Record-Hot Spring in Korea ................................................... 95

20. Human Contribution to the 2014 Record High Sea Surface Temperatures Over the Western Tropical And Northeast Pacific Ocean.....

21. The 2014 Hot, Dry Summer in Northeast Asia 105

22. Role of Anthropogenic Forcing in 2014 Hot Spring in Northern China

23. Investigating the Influence of Anthropogenic Forcing and Natural Variability on the 2014 Hawaiian Hurricane Season.

24. Anomalous Tropical Cyclone Activity in the Western North Pacific in August 2014

25. The 2014 Record Dry Spell at Singapore: An Intertropical Convergence Zone (ITCZ) Drought

26. Trends in High-Daily Precipitation Events in Jakarta and the Flooding of January 2014 ................ 131

27. Extreme Rainfall in Early July 2014 in Northland, New Zealand-Was There an Anthropogenic Influence?

28. Increased Likelihood of Brisbane, Australia, G20 Heat Event Due to Anthropogenic Climate Change

29. The Contribution of Anthropogenic Forcing to the Adelaide and Melbourne, Australia, Heat Waves of January 2014

30 Contributors to the Record High Temperatures Across Australia in Late Spring 2014 ............... 149

3I. Increased Risk of the 2014 Australian May Heatwave Due to Anthropogenic Activity............... I54

32. Attribution of Exceptional Mean Sea Level Pressure Anomalies South of Australia in August 2014

33. The 2014 High Record of Antarctic Sea Ice Extent........................................................................ 163

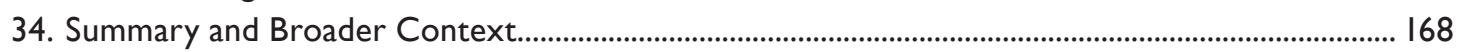




\section{ABSTRACT_Stephanie C. Herring, Martin P. Hoerling, James P. Kossin, Thomas C. Peterson, and Peter A. Stott}

Understanding how long-term global change affects the intensity and likelihood of extreme weather events is a frontier science challenge. This fourth edition of explaining extreme events of the previous year (2014) from a climate perspective is the most extensive yet with 33 different research groups exploring the causes of 29 different events that occurred in 2014. A number of this year's studies indicate that human-caused climate change greatly increased the likelihood and intensity for extreme heat waves in 2014 over various regions. For other types of extreme events, such as droughts, heavy rains, and winter storms, a climate change influence was found in some instances and not in others. This year's report also included many different types of extreme events. The tropical cyclones that impacted Hawaii were made more likely due to human-caused climate change. Climate change also decreased the Antarctic sea ice extent in 2014 and increased the strength and likelihood of high sea surface temperatures in both the Atlantic and Pacific Oceans. For western U.S. wildfires, no link to the individual events in 2014 could be detected, but the overall probability of western U.S. wildfires has increased due to human impacts on the climate.
Challenges that attribution assessments face include the often limited observational record and inability of models to reproduce some extreme events well. In general, when attribution assessments fail to find anthropogenic signals this alone does not prove anthropogenic climate change did not influence the event. The failure to find a human fingerprint could be due to insufficient data or poor models and not the absence of anthropogenic effects.

This year researchers also considered other humancaused drivers of extreme events beyond the usual radiative drivers. For example, flooding in the Canadian prairies was found to be more likely because of human land-use changes that affect drainage mechanisms. Similarly, the Jakarta floods may have been compounded by land-use change via urban development and associated land subsidence. These types of mechanical factors reemphasize the various pathways beyond climate change by which human activity can increase regional risk of extreme events. 


\title{
9. CAUSAL INFLUENCE OF ANTHROPOGENIC FORCINGS ON THE ARGENTINIAN HEAT WAVE OF DECEMBER 2013
}

\author{
A. Hannart, C. Vera, F. E. L. Otto, and B. Cerne
}

The Argentinian heat wave of December 2013 was likely caused in part by anthropogenic forcings. These forcings have increased the risk of such an event occurring by a factor of five.

Introduction. A heat wave occurred 13-31 December 2013 in the Northern and central area of Argentina as well as in Northern Patagonia (Fig. 9.1a). Since the beginning of the temperature record by the Argentine National Meteorological Service (SMN), the year 2013 had the hottest month of December ever recorded over the impacted area $\left(+2.5^{\circ} \mathrm{C}\right.$ anomaly with respect to 1961-90). In the Greater Buenos Aires area, which is the second largest urban area in South America, the event stands out as the single longest heat wave that ever occurred (18 days) over the observational period. This event had significant impacts in particular on the health and energy sectors.

The analysis of the atmospheric dynamics shows that the high temperatures were primarily associated with an intensification of the South Atlantic Convergence Zone (SACZ), which jointly caused simultaneous extreme rainfall events in Southeastern Brazil (Fig. 9.1b). While particularly apparent in the case of the December 2013 heat wave, the influence of the SACZ on heat waves over this subtropical region is a mechanism that has been previously well described (Cerne et al. 2007; Cerne and Vera 2011) and can be summarized as follows: (i) intensified SACZ promotes subsidence over Argentina, favoring clear sky conditions and increasing incoming solar radiation; (ii) which in turn generates high temperatures and lack of rainfall (Fig. 9.1a,b). Furthermore, this mechanism is reinforced in general, and in particular during December 2013, by the presence of an anticyclonic circulation anomaly over central Argentina, which in turn is modulated by Rossby wave trains extended along the South Pacific (Fig. 9.1c), likely induced in

AFFILIATIONS: HANNART-Institut Franco-Argentin d'études sur le climat et ses impacts (IFAECI), Centre National de la Recherche Scientifique (CNRS)/Consejo Nacional de Investigaciones Científicas y Técnicas (CONICET)/University of Buenos Aires, Argentina; OTTO-Environmental Change Institute, University of Oxford, United Kingdom

DOI:I0.1175/BAMS-D-15-00137.I part by increased tropical convection over Northern Australia and the Maritime continent (not shown).

From a long-term climate perspective, previous studies (Rusticucci 2012) documented significant trends in some temperature features in the region: while minimum temperatures clearly exhibit positive trends-particularly in Central and Eastern Argentina during the second part of the twentieth century and first decade of the twenty-first century-maximum temperatures, on the contrary, show significant negative trends. On the other hand, there is only medium confidence in the increase of warm extremes of minimum temperature in this region, and trends in maximum temperature extremes are characterized by high spatial variability. Few studies analyzed the trends related to heat waves or warm spells, which appear to have increased in some areas and decreased in others (Seneviratne et al. 2012; Perkins et al. 2012; Rusticucci et al. 2015).

While the causes of the event associated with the short-term dynamics of the atmosphere are well understood, it is not clear at present whether or not the long-term climate response to anthropogenic forcing can also be held to have causally contributed to the occurrence of the event. The present work addresses the latter causal aspects.

Data and method. A heat wave is defined to occur when the index of surface temperature averaged over the relevant area $\left(23^{\circ}-45^{\circ} \mathrm{S}, 75^{\circ}-55^{\circ} \mathrm{W}\right.$; see Fig. 9.1a) and over the month of December ( $Z$ hereafter) reaches or exceeds a threshold which will be discussed further. Observed values of $Z$ over the instrumental period were calculated from the South American gridded dataset (SAG hereafter; Tencer et al. 2011). Since this dataset only covers the period 1960-2000, the periods 1901-60 and 2001-14 were obtained from HadCRUT4 (Morice et al. 2012) anomalies added to SAG climatology. The choice to use climatology from SAG is justified by the fact that it has better spatial 

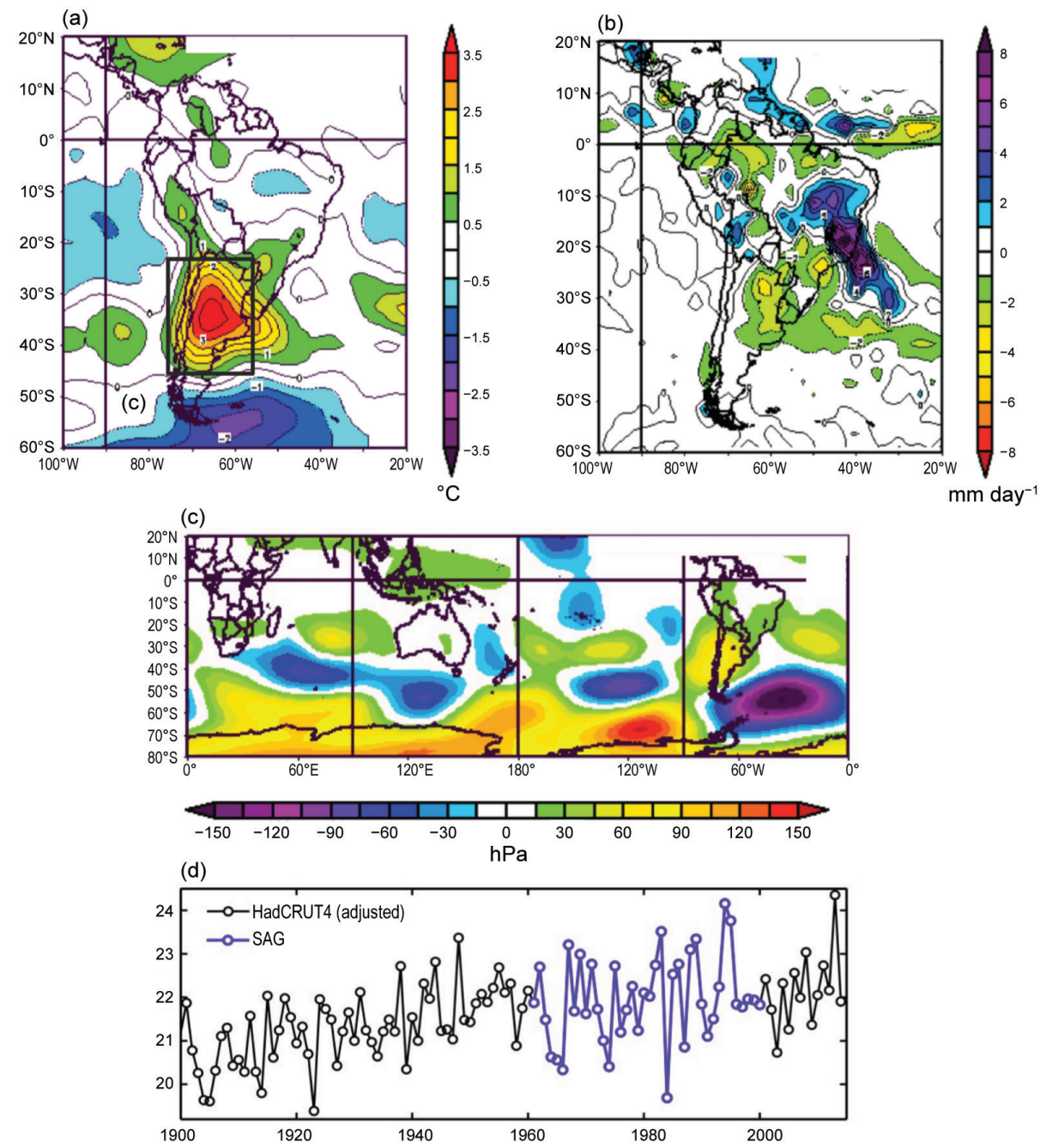

Fıg. 9.I. Observations. (a,b,c) Atmospheric dynamics associated with the event: monthly anomalies with respect to 198I-2010 climatological average for Dec 2013 over South America (a,b) and Southern Hemisphere (c) obtained from NCEP-NCAR reanalysis dataset and plotted using the website esrl.noaa.gov/ psd (NOAA/ESRL Physical Sciences Division, Boulder, CO, USA). (a) Surface temperature ( $\left.{ }^{\circ} \mathrm{C}\right)$. (b) Precipitation ( $\left.\mathrm{mm}_{\text {day }}{ }^{-1}\right)$. (c) Sea level pressure (hPa). (d) Time series of the temperature index $Z$ (space-time average over the domain $23^{\circ}-45^{\circ} \mathrm{S}, 75^{\circ}-55^{\circ} \mathrm{W}$, month of $\mathrm{Dec}$ ) over the instrumental period obtained from SAG and HadCRUT4.

coverage and underwent a more detailed quality control than HadCRUT4.

Following standard practices for causal attribution (Allen 2003; Hannart et al. 2015), we analyzed whether and to what extent anthropogenic climate change changed the odds of a heat wave in central Argentina in December. We thus compared P1, the probability of occurrence of a heat wave under the observed climate conditions of 2013 (referred to as factual conditions) to $\mathrm{P} 0$, the same probability in the world as it might have been without anthropogenic climate change (referred to as counterfactual). For this purpose, we followed the method of Schaller et al. (2014) and we used the distributed computing framework weather@home to run the Met Office Hadley Centre atmosphere-only general circulation model HADAM3P (Massey et al. 2015), which has been shown to adequately represent some key features of atmospheric circulation over South America (Chou et al. 2012). We generated two ensembles: (i) observed climate conditions of 2013, forced with observed aerosols and greenhouse gas composition as well as SST and sea ice fraction values from 2013 obtained from the Operational Sea Surface Temperature and Sea Ice Analysis (OSTIA) dataset (Stark et al. 2007); (ii) counterfactual conditions, forced with preindustrial atmospheric gas composition, combined with the sea ice extent that corresponds to the year of maximum sea ice extent in each hemisphere of the OSTIA record, and with 11 different estimates of sea surface temperatures (SSTs) without human influence. These SSTs are obtained by subtracting 11 estimates of the human influence on SST from the 2013 OSTIA SST values. These 11 SST anomaly patterns are obtained by calculating the difference between nonindustrial and present-day simulations for available Coupled Model Intercomparison Project Phase 5 (CMIP5) models.

Two PDFs of the temperature index $\mathrm{Z}$ were estimated from these two ensembles, under Gaussian assumption. The so-called fraction of attributable risk $(\mathrm{FAR}=1-\mathrm{P} 0 / \mathrm{P} 1)$ was then derived; Hannart et al. (2015) have shown that in causal theory (Pearl 2000), the FAR may also be interpreted as the probability of necessary causation (PN) associated with 
the causal link between the forcing and the event. A prominent feature of causal theory indeed consists of recognizing that causation corresponds to rather different situations and that three distinct facets of causality should be distinguished: (i) necessary causation, where the occurrence of the event requires that of the forcing but may also require other factors; (ii) sufficient causation, where the occurrence of the forcing drives that of the event but may not be required for the event to occur; (iii) necessary and sufficient causation, where (i) and (ii) both hold. The probability of necessary causation (PN) thus corresponds to only one of the three facets of causality, while the probability of sufficient causation PS $=1-(1-\mathrm{P} 1) /(1-\mathrm{P} 0)$ is its second facet, and the probability of necessary and sufficient causation PNS $=$ P1 - P0 summarizes both. With these definitions, the choice of the threshold on $\mathrm{Z}$ that defines occurrence has critical implications on the amount and nature of causal evidence (Fig. 9.2d). In the context of extreme event attribution, many different factors are usually necessary to trigger the occurrence of a rare event and, conversely, no single factor will ever hold as a sufficient explanation thereof: maximizing $\mathrm{PN}$ at the expense of PS is thus arguably a relevant approach in the present context. Here, this implies choosing the highest possible threshold for the index, that is $24.4^{\circ} \mathrm{C}$ (Fig. 9.2d).

Results. The observed time series over the period 1900-2014 is shown in Fig. 9.1d. The climatological mean calculated over the period 1961-90 is $21.9^{\circ} \mathrm{C}$ with anomalies ranging from $-2.5^{\circ} \mathrm{C}$ in year 1923 to $+2.5^{\circ} \mathrm{C}$ in year 2013, which is therefore the record high year over the instrumental period.

The factual and counterfactual PDFs are shown in Figs. 9.2a-c. They differ significantly, and their difference can be described quite straightforwardly: it merely consists of $\mathrm{a} \sim 1^{\circ} \mathrm{C}$ gap in their mean, while their dispersion, shape, and tails are roughly unchanged. Thereby, the intensity level of a heat wave is higher in the factual world than it would be in the counterfactual one for any return period, and the level is increased by $1^{\circ} \mathrm{C}$ no matter the return period. Figs. 9.2a,b emphasize this finding: one can see that the return level curves match well with each other, up to a $1^{\circ} \mathrm{C}$ translation. On the other hand, the tail behavior (a)

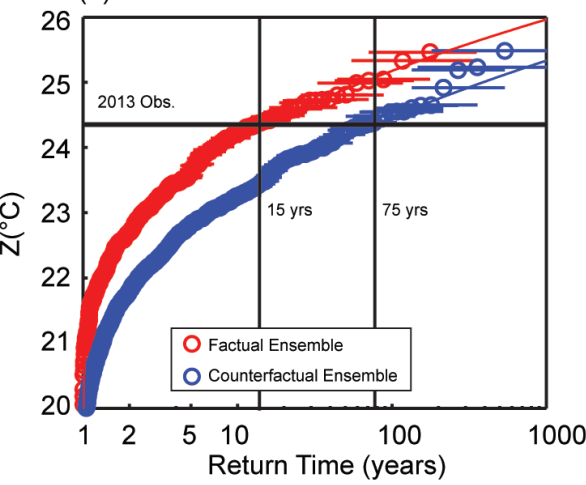

(c)

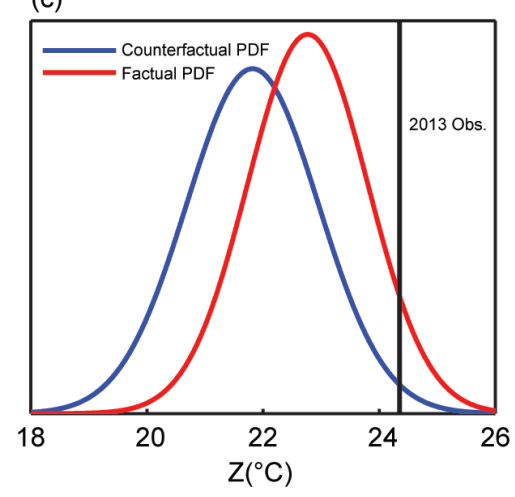

(b)

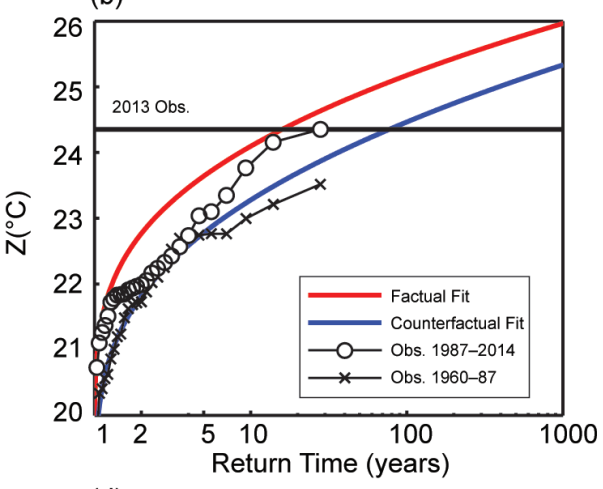

(d)

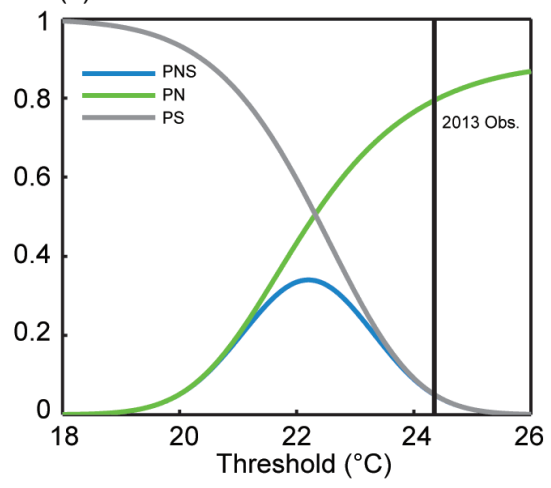

Fig. 9.2. Simulations. $(a, b, c)$ Comparison of the factual vs counterfactual PDFs of the temperature index Z. (a) Return level curves simulated by HADAM3P: factual values (red dots) and counterfactual values (blue dots), 95\% confidence interval (thin horizontal bars), Gaussian fit (red and blue lines), observed Dec 2013 value (thick horizontal black line), return periods (thin vertical black lines). (b) Same as (a) with superimposed observations over the 1960-87 (black line with crosses) and 1987-20I4 (black line with circles) periods. (c) Factual and counterfactual PDFs of Z (Gaussian fit), observed Dec 2013 value (thick vertical black line). (d) PN, PS, and PNS as a function of the threshold used for event definition. Adopting a less restrictive definition (i.e., smaller threshold) decreases the level of necessity but increases that of sufficiency-which of these matters most depends on the purpose of the causal question (Hannart et al., 2015). A possible "multipurpose" approach is to balance both quantities, but this leads here to a substantially lower threshold ( $u=22.3^{\circ} \mathrm{C}$; 1.5 and 3.5 year return periods) which no longer reflects the extreme nature of the event and yields a well-balanced but not very stringent level of causal evidence. Maximizing PN at the expense of very low PS is arguably more relevant here, yielding $\mathrm{PN}=0.8$ and $\mathrm{PS}=0.07$. 
of the two PDFs appears to be accurately described by a Gaussian distribution. The quality of the Gaussian fit is apparent in Fig. 9.2a where the empirical and the theoretical Gaussian return level curves are almost indistinguishable.

Figure 9.2b shows that simulated PDFs represent reasonably well the distribution of observed values without requiring any bias correction. Indeed, the return level curve obtained from observations over the period 1987-2014 (respectively 1960-87) appears to match decently well with the simulated return level curve in the factual (respectively counterfactual) world.

Discussion and conclusion. The value of the index reached in 2013 corresponds to a return period of 15 years in the factual world and a return period of 75 years in the counterfactual one (Fig. 9.2a): exceeding the intensity of the December 2013 heat wave thus appears to be five times more likely in the world as it was in 2013, than it was in the same world with no anthropogenic forcings.

This ratio corresponds to FAR $=80 \%$, and it is consequently tempting to claim that $80 \%$ of the risk of the December 2013 heat wave is attributable to anthropogenic forcings. But this statement may be considered as a somewhat misleading interpretation. Indeed, the FARs associated to other causes, whether natural or anthropogenic, could be high as well. In any case, the FARs associated to the many causes of an extreme event are never bound to sum up to one, therefore the FAR can not be interpreted as a "share" of causality as the above statement suggests. It could thus be more appropriate to rename the acronym FAR into "fraction of additional risk."

Finally, the probabilistic definitions of causality recalled above offer yet a different causal interpretation and formulation. In the present case, $\mathrm{PN}=0.8$ and $\mathrm{PS}=0.07$ yields the statement that anthropogenic forcings were likely a necessary cause of the December 2013 heat wave, and yet were very likely not a sufficient cause thereof-a statement which clearly reflects the fact that other causal factors were involved in this event, and which may be shortened into "The Argentinian heat wave of December 2013 was likely caused in part by anthropogenic forcings."

ACKNOWLEDGEMENTS. We thank colleagues at the Oxford eResearch Centre and the Met Office Hadley Centre (PRECIS team) for their expertise, and the volunteers who have donated computing time to climateprediction.net. We gratefully acknowledge useful suggestions by three anonymous reviewers and an inspiring discussion with Peter Stott, which improved the manuscript. This research was supported by grant ANR-DADA (AH), and grants UBACyT 20020130100489BA and CONICET-PIP 11220120100536 (CV, BC).

\section{REFERENCES}

Allen, M. R., 2003: Liability for climate change. Nature, 421, 891-892.

Cerne, B., and C. Vera, 2011: Influence of the intraseasonal variability on heat waves in subtropical South America. Climate Dyn., 36, 2265-2277, doi:10.1007 /s00382-010-0812-4.

_ _ _ and B. Liebmann, 2007: The nature of a heat wave in eastern Argentina occurring during SALLJEX. Mon. Wea. Rev., 135, 1165-1174.

Chou, S. C., and Coauthors, 2012: Downscaling of South America present climate driven by 4 -member HadCM3 runs. Climate Dyn., 38, 635-653, doi:10.1007/s00382-011-1002-8.

Hannart, A., J. Pearl, F. E. L. Otto, P. Naveau, and M. Ghil, 2015: Counterfactual causality theory for the attribution of weather and climate-related events. Bull. Amer. Meteor. Soc., doi:10.1175 /BAMS-D-14-00034.1, in press.

Massey, N., and Coauthors, 2015: weather@home-development and validation of a very large ensemble modelling system for probabilistic event attribution. Quart. J. Roy. Meteor. Soc. 141, 1528-1545, doi:10.1002/qj.2455.

Morice, C. P., J. J. Kennedy, N. A. Rayner, and P. D. Jones, 2012: Quantifying uncertainties in global and regional temperature change using an ensemble of observational estimates: The HadCRUT4 dataset. J. Geophys. Res., 117, D08101, doi:10.1029/2011JD017187.

Pearl, J., 2000: Causality: Models, Reasoning and Inference. Cambridge University Press, $484 \mathrm{pp}$.

Perkins, S. E., L. V. Alexander, and J. R. Nairn, 2012: Increasing frequency, intensity and duration of observed global heatwaves and warm spells. Geophys. Res. Lett., 39, L20714, doi:10.1029/2012GL053361.

Rusticucci, M., 2012: Observed and simulated variability of extreme temperature events over South America. Atmos. Res., 106, 1-17, doi:10.1016 /j.atmosres.2011.11.001. 
— - J. Kyselý, G. Almeira, and O. Lhotka, 2015: Longterm variability of heat waves in Argentina and recurrence probability of the severe 2008 heat wave in Buenos Aires. Theor. Appl. Climatol., doi:10.1007 /s00704-015-1445-7, in press.

Schaller, N., F. E. L. Otto, G. J. van Oldenborgh, N. R. Massy, S. Sparrow, and M. R. Allen, 2014: The heavy precipitation event of May-June 2013 in the upper Danube and Elbe basins [in "Explaining Extreme Events of 2013 from a Climate Perspective"]. Bull. Amer. Meteor. Soc., 95 (9), S69-S72.

Seneviratne, S. I., and Coauthors, 2012: Changes in climate extremes and their impacts on the natural physical environment. Managing the Risks of Extreme Events and Disasters to Advance Climate Change Adaptation, C. B. Field et al., Eds., Cambridge University Press, 109-230.

Stark J. D., C. J. Donlon, M. J. Martin, and M. E. McCulloch, 2007: OSTIA: An operational, high resolution, real time, global sea surface temperature analysis system. Oceans 2007 - Europe, Aberdeen, Scotland, IEEE, 331-334, doi:10.1109 /OCEANSE.2007.4302251.

Tencer, B., M. Rusticucci, P. D. Jones, and D. Lister, 2011: A southwestern South American daily gridded data set of observed surface minimum and maximum surface temperature for 1960-2000. Bull. Amer. Meteor. Soc., 92, 1339-1346, doi:10.1175/2011BAMS3148.1. 


\begin{tabular}{|c|c|c|c|}
\hline \multicolumn{4}{|c|}{ ON EVENT STRENGTH † } \\
\hline & INCREASE & DECREASE & NOT FOUND OR UNCERTAIN \\
\hline Heat & $\begin{array}{l}\text { Australia (Ch. 3I) } \\
\text { Europe (Ch. I3) } \\
\text { S. Korea (Ch. 19) }\end{array}$ & & $\begin{array}{l}\text { Australia, Adelaide \& Melbourne } \\
\text { (Ch. 29) } \\
\text { Australia, Brisbane (Ch.28) }\end{array}$ \\
\hline Cold & & Upper Midwest (Ch.3) & \\
\hline $\begin{array}{l}\text { Winter } \\
\text { Storms and } \\
\text { Snow }\end{array}$ & & & $\begin{array}{l}\text { Eastern U.S. (Ch. 4) } \\
\text { N. America (Ch. 6) } \\
\text { N. Atlantic (Ch. 7) }\end{array}$ \\
\hline $\begin{array}{c}\text { Heavy } \\
\text { Precipitation }\end{array}$ & Canada** (Ch. 5) & & $\begin{array}{l}\text { Jakarta**** (Ch. 26) } \\
\text { United Kingdom } * * *(C h . ~ 10) \\
\text { New Zealand (Ch. 27) }\end{array}$ \\
\hline Drought & $\begin{array}{l}\text { E. Africa (Ch. 16) } \\
\text { E. Africa* (Ch. I7) } \\
\text { S. Levant (Ch. 14) }\end{array}$ & & $\begin{array}{l}\text { Middle East and S.W. Asia } \\
\text { (Ch. I5) } \\
\text { N.E. Asia (Ch. 2I) } \\
\text { Singapore (Ch. 25) }\end{array}$ \\
\hline $\begin{array}{l}\text { Tropical } \\
\text { Cyclones }\end{array}$ & & & $\begin{array}{l}\text { Gonzalo (Ch. II) } \\
\text { W. Pacific (Ch. 24) }\end{array}$ \\
\hline Wildfires & & & California (Ch. 2) \\
\hline $\begin{array}{l}\text { Sea Surface } \\
\text { Temperature }\end{array}$ & $\begin{array}{l}\text { W. Tropical \& N.E. Pacific (Ch. 20) } \\
\text { N.W. Atlantic \& N.E. Pacific (Ch. 13) }\end{array}$ & & \\
\hline $\begin{array}{l}\text { Sea Level } \\
\text { Pressure }\end{array}$ & S. Australia (Ch. 32) & & \\
\hline $\begin{array}{l}\text { Sea Ice } \\
\text { Extent }\end{array}$ & & & Antarctica (Ch. 33) \\
\hline
\end{tabular}

† Papers that did not investigate strength are not listed.

†† Papers that did not investigate likelihood are not listed.

* No influence on the likelihood of low rainfall, but human influences did result in higher temperatures and increased net incoming radiation at the surface over the region most affected by the drought.

** An increase in spring rainfall as well as extensive artificial pond drainage increased the risk of more frequent severe floods from the enhanced rainfall.

*** Evidence for human influence was found for greater risk of UK extreme rainfall during winter 20I3/14 with time scales of 10 days

**** The study of Jakarta rainfall event of 2014 found a statistically significant increase in the probability of such rains over the last 115 years, though the study did not establish a cause. 


\section{ON EVENT LIKELIHOOD ††}

Argentina (Ch. 9)

Australia (Ch. 30, Ch. 3I)

Australia, Adelaide (Ch. 29)

Heat

Australia, Brisbane (Ch. 28)

Melbourne, Australia (Ch. 29)

Europe (Ch. 13)

S. Korea (Ch. 19)

China (Ch. 22)

\section{Cold}

\begin{tabular}{|l|l}
\hline Upper Midwest (Ch.3) \\
\hline
\end{tabular}

Winter

Storms and

Snow

Nepal (Ch. 18)

Eastern U.S.(Ch. 4)

N. America (Ch. 6)

N. Atlantic (Ch. 7)

Heavy

Canada** (Ch. 5)

Jakarta**** (Ch. 26)

United Kingdom*** (Ch. 10)

S. France (Ch. I2)

Middle East and S.W. Asia (Ch. 15)

E. Africa* (Ch. 17)

Drought

E. Africa (Ch. 16)

N.E. Asia (Ch. 2l)

S. Levant (Ch. 14)

S. E. Brazil (Ch. 8)

Singapore (Ch. 25)

Tropical
Cyclones
Wildfires

Sea Surface
Temperature

Hawaii (Ch. 23)

Gonzalo (Ch. II)

W. Pacific (Ch. 24)

California (Ch. 2)

W. Tropical \& N.E. Pacific

(Ch. 20)

N.W. Atlantic \& N.E. Pacific

(Ch. 13)

\begin{tabular}{l} 
Sea Level \\
Pressure \\
\hline Sea Ice \\
Extent
\end{tabular}

S. Australia (Ch. 32)

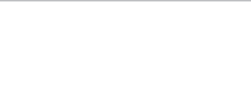

Antarctica (Ch. 33)

† Papers that did not investigate strength are not listed.

t† Papers that did not investigate likelihood are not listed.

* No influence on the likelihood of low rainfall, but human influences did result in higher temperatures and increased net incoming radiation at the surface over the region most affected by the drought.

** An increase in spring rainfall as well as extensive artificial pond drainage increased the risk of more frequent severe floods from the enhanced rainfall.

*** Evidence for human influence was found for greater risk of UK extreme rainfall during winter 2013/14 with time scales of 10 days

**** The study of Jakarta rainfall event of 2014 found a statistically significant increase in the probability of such rains over the last 115 years, though the study did not establish a cause. 